\title{
Quasi-CW Laser Diode Bar Life Tests
}

\author{
M. A. Stephen, M. A. Krainak \\ NASA / GSFC - Code 554 \\ Greenbelt, MD 20771 \\ E-mail: mark.stephen@ysfc.nasa.gov \\ Phone: (301) 286-3245 \\ J. L. Dallas \\ Science Systems and Applications. Inc. \\ Lanham, MD
}

\begin{abstract}
NASA's Goddard Space Flight Center is developing technology for satellite-based, high peak power, LIDAR transmitters requiring 3-5 years of reliable operation. Semi-conductor laser diodes provide high efficiency pumping of solid state lasers with the promise of long-lived, reliable operation. 100-watt quasi$\mathrm{CW}$ laser diode bars have been baselined for the next generation laser altimeters. Multi-billion shot lifetimes are required. The authors have monitored the performance of several diodes for billions of shots and investigated operational modes for improving diode lifetime.
\end{abstract}

Keywords: laser diode bar, lifetest

\section{MOTIVATION}

NASA's Goddard Space Flight Center (GSFC) is developing technology for satellite-based, high peak power, LIDAR transmitters. The Geoscience Laser Altimeter System (GLAS) is scheduled to launch in 2001 and requires a $40 \mathrm{~Hz}, 110 \mathrm{~mJ}, 4 \mathrm{~ns}, \mathrm{Nd}$ :YAG laser transmitter to run continuously for 5 years in space. 'The most efficient optical pump sources for such a laser are semiconductor quasi-CW (QCW) laser diode arrays. However, the reliability of these diodes is in question. Laser diode bars are the only known source of degradation limiting the long-term survivability of the laser.. ${ }^{2,3}$ The multi-billion shot performance of $100 \mathrm{~W}$ peak power $\mathrm{QCW}$ laser diode bars is investigated along with operational modes for improving diode lifetime.

\section{MULTI-BILLION SHOT PERFORMANCE TESTS}

A dedicated laser diode performance station was established on an optical bench within a secure, white room laboratory. The output power from each diode was collected in an integrating sphere fitted with a calibrated power meter. Dedicated drivers (SDL 928) powered each laser diode with constant current. This research utilized only laser diodes produced by SDL, Inc. At the time, they were the only laser diode manufacturer of $100 \mathrm{~W}$ QCW diode bars advertising billion shot operation before endof-life (EOL - defined as $20 \%$ degrade). All the laser diodes tested were packaged by the vendor in their standard water-cooled assemblies (SDL $3255-\mathrm{C}$ ). This allowed maximum pulse repetition rate operation for accelerated life tests. A NESLAB CFT-33 chiller supplied temperature controlled water circulation. While operating 24 hours/day, a computer running LabView autonomously monitored instruments measuring the optical power, pulse count, diode drive current, diode temperature, and 
ambient temperature and humidity. An interlock circuit, attached to each diode power supply, disabled the drive current if the diode temperature rose above a set-point; protecting the diode from chiller failure or thermal runaway.

The performance of nine diodes operated for billions of shots is illustrated in Figure and Table 1. Diodes U 350 and U920 show less frequent sampling because they were used in separate accelerated tests while pumping a laser crystal. ${ }^{2.3}$

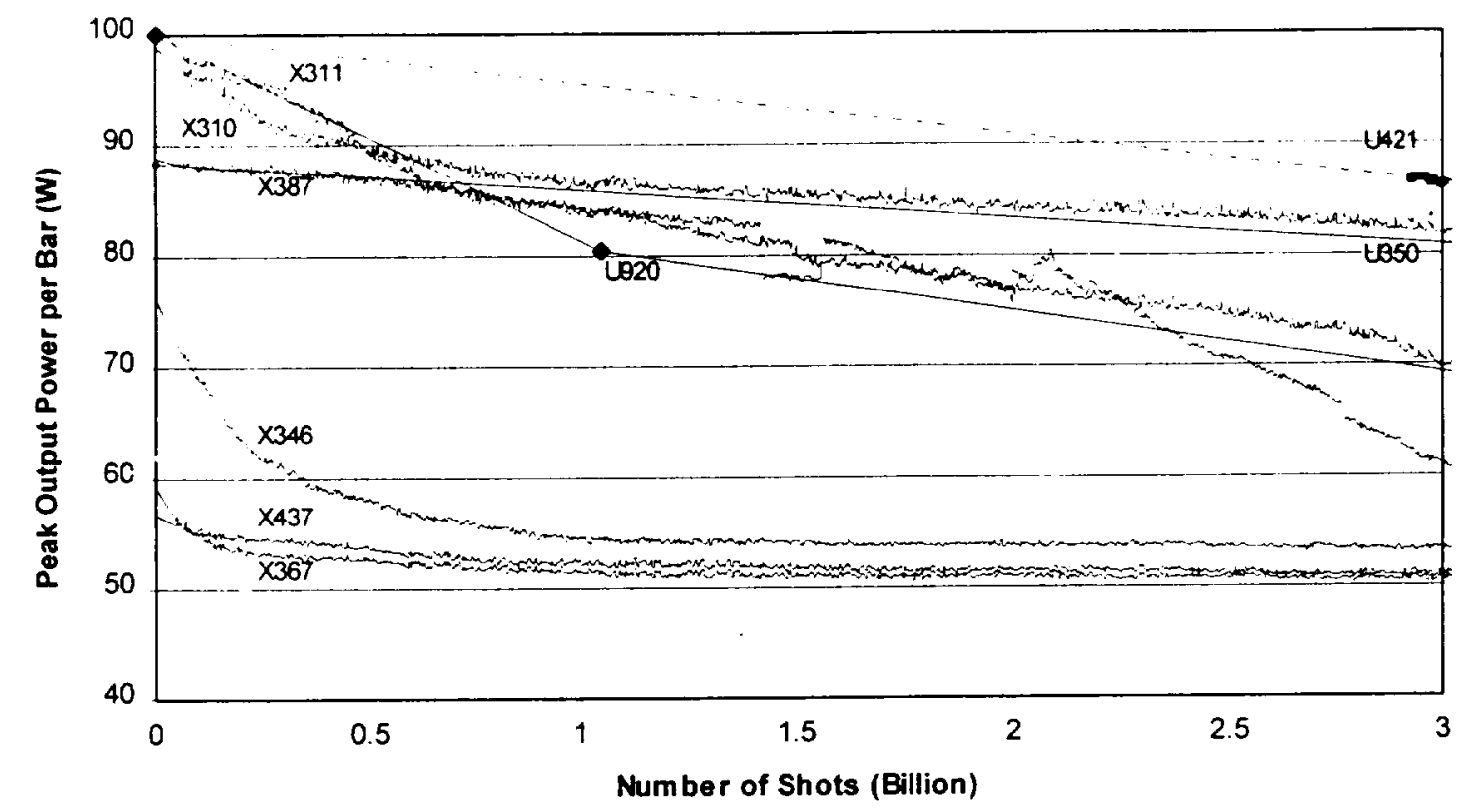

Figure 1. - Output power degradation of 9 laser diode bars over multi-billion shots.

\begin{tabular}{|c|c|c|c|c|c|c|c|}
\hline $\begin{array}{c}\text { Serial } \\
\text { Number }\end{array}$ & $\begin{array}{c}\text { \# bars / } \\
\text { package }\end{array}$ & $\begin{array}{c}\text { Duty Cycle } \\
(\%)\end{array}$ & $\begin{array}{c}\text { Optical Power } \\
\text { De-Rate (\%) }\end{array}$ & Temp $\left({ }^{\circ} \mathrm{C}\right)$ & $\begin{array}{c}\text { Total \# } \\
\text { Shots }\left(10^{\circ}\right)\end{array}$ & $\begin{array}{c}\text { Total Degrade } \\
(\%)\end{array}$ & $\begin{array}{c}\text { EOL } \\
\left(10^{9}\right)\end{array}$ \\
\hline $\mathrm{U} 421$ & 3 & 4 & 0 & 25 & 5 & 23 & 5 \\
\hline $\mathrm{U} 350$ & 1 & 10 & 10 & 24 & 7 & 20 & 7 \\
\hline $\mathrm{U} 920$ & 1 & 10 & 0 & 24 & 15 & 45 & 1 \\
\hline $\mathrm{X} 310$ & 1 & 4 & 0 & 30 & 3 & 17.2 & - \\
\hline $\mathrm{X} 311$ & 1 & 4 & 0 & 20 & 3 & 31.7 & 1.5 \\
\hline $\mathrm{X} 387$ & 1 & 4 & 12 & 30 & 3 & 32.8 & 2.47 \\
\hline $\mathrm{X} 346$ & 1 & 4 & 25 & 20 & 3 & 31.5 & 0.33 \\
\hline $\mathrm{X}+37$ & 1 & 4 & 40 & 30 & 3 & 10.7 & - \\
\hline $\mathrm{X} 367$ & 1 & 4 & 40 & 20 & 3 & 14.3 & - \\
\hline
\end{tabular}

Table 1. - Operating conditions and results of billion shot performance tests of SDL-3255 laser diode bars. End-of-life (EOL) is defined as the $20 \%$ degrade point. 


\section{INVESTIGATION OF RELIABILITY PARAMETERS}

In addition to monitoring laser diode performance for billions of shots. we investigated operational modes for improving lifetime. The tests performed on the " $X$-..." Series diodes at GSFC ( Figure and Table 1) were designed to observe effects of de-rated power and decreased heatsink temperature. In this test, six one-bar stacks in water-cooled packages (SDL $3255-\mathrm{Cl}$ ) were run in pairs at constant current. Two diodes were run at $93 \mathrm{amps}$, two at $109 \mathrm{amps}$, and two at $121 \mathrm{amps}$. One of each of these diode pairs was run at a heatsink temperature of $20^{\circ} \mathrm{C}$; the other at $30^{\circ} \mathrm{C}$. Each diode pair (same current) was powered with a single current driver while each diode triplet (same temperature) was cooled with a single water chiller. For each of the diode pairs running at the same current, the more efficient diode was run at the warmer temperature, so the optical powers would be closer and power de-rate more comparable.

In tests performed at SDL, Inc. (sponsored by NASA/GSFC, GLAS Project) four, 6-bar stacks (SDL 3252-H6) were operated for billions of shots: one stack at $100 \mathrm{~W}$ peak optical power, one at $80 \mathrm{~W}$ and two at $60 \mathrm{~W}^{4}$. This test was designed to isolate the effect of de-rating the peak optical power of the laser diode arrays from facet temperature effects. This was accomplished by increasing the duty cycle of arrays with lower peak optical power so that all the arrays operated at the same average optical power and thus the same facet temperature $\left(30^{\circ} \mathrm{C}\right.$ ). (See Figure and Table 2.) In this test, the diode drive currents were periodically adjusted to keep the peak optical output power constant.

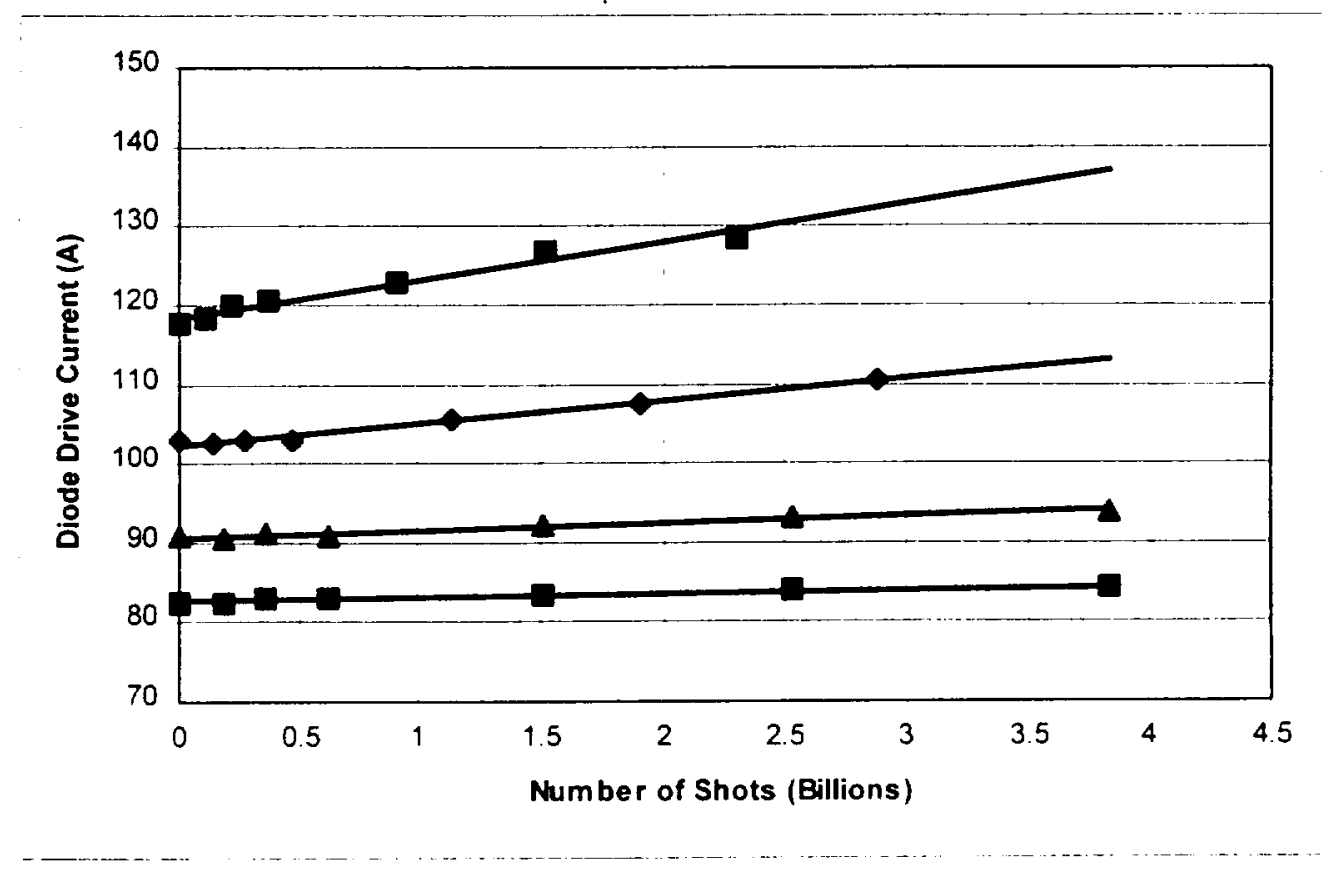

Figure 2. SDL performance test of 3252-H6 $100 \mathrm{~W} Q \mathrm{CW}$ laser diode bars at constant optical power. The heatsink and diode junction temperatures are held constant. 


\begin{tabular}{|c|c|c|c|c|c|c|c|}
\hline $\begin{array}{c}\text { Serrial } \\
\text { Number }\end{array}$ & $\begin{array}{l}\text { A hatri } \\
\text { packiage }\end{array}$ & $\begin{array}{c}\text { Duly (ycte } \\
(0,0)\end{array}$ & $\begin{array}{l}\text { (Iptacial Power } \\
\text { De-Ralte }\left({ }^{\prime \prime n}\right)\end{array}$ & limpl"(') & $\begin{array}{c}\text { lolal if } \\
\text { Shots }\left(100^{\prime \prime}\right)\end{array}$ & $\begin{array}{c}\text { Cotal Degeriade } \\
(00)\end{array}$ & $\begin{array}{c}\text { SI I is l'redicted } \\
1:(0)\left(100^{\prime \prime}\right)\end{array}$ \\
\hline$\times 342$ & 6 & y) & 1) & 20 & 2.3 & 9.1 & 4.9 \\
\hline$\times 389$ & 6 & 11.2 & 20 & 20 & 2.8 & 7.3 & 7.9 \\
\hline$\times 340$ & 6 & 15 & 4) & 20 & 3.8 & 3.5 & 22 \\
\hline$\overline{x 391}$ & 6 & 15 & 40) & 20 & 3.8 & 2.2 & 35 \\
\hline
\end{tabular}

Table 2. Operating conditions and results of billion shot performance

Tests of SDL 3252-H6 laser diode arrons.

Both the GSFC and SDL tests demonstrate an advantage in long-term performance from de-rating optical power. From our admittedly small statistical sample, if you draw a straight line through the data, then an increase of 3.5 billion shots in laser diode life is realized for every $10 \%$ in optical peak power derating. There was no significant improvement in diode performance for the units which were operated at a $10^{\circ}$ cooler temperature; $20^{\circ}$ versus $30^{\circ}$. In general, the diode electrical-to-optical efficiency is a better. predictor for long term performance. The more electrically efficient diodes degraded slower than less efficient diodes, under similar operating conditions.

The emission wavelength and number of active emitters, for the GSFC " $\mathrm{X}$--." series diodes, were also recorded over billions of shots. At 500 million shot intervals, the laser diode wavelengths were measured using an integrating sphere fiber coupled to a Hewlett Packard 7095 1 A optical spectrum analyzer. Figure 3 illustrates the change in the peak emission wavelength of the laser diodes over billions of shots.

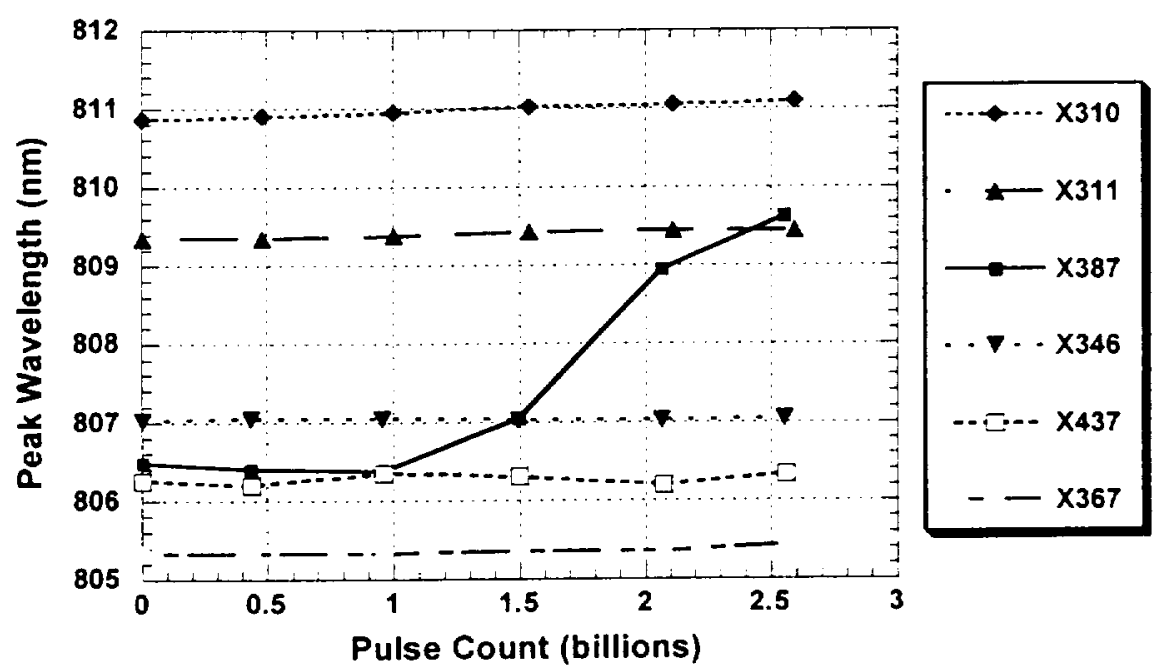

Figure 3. - Peak emission wavelength of laser diode bars recorded over billions of shots.

It is reasonable to assume that as the laser diode degrades, a growing fraction of the electrical drive power, which is no longer converted and emitted as optical power, will be absorbed by the diode, thereby generating additional heat. Heating the diode package shifts the peak emission wavelength by $0.3 \mathrm{~nm} /{ }^{\circ} \mathrm{C}$. In Table 3, the diode optical power degrade $(\Delta P)$, calculated temperature rise $(\Delta T)$, and finally calculated wavelength shift $(\Delta \lambda)$ are compared to the measured wavelength shift. 


\begin{tabular}{|c|c|c|c|c|}
\hline Diode & Output $\mathbf{J P}(\mathbf{W})$ & Calculated $\triangle T(C)$ & Calculated $\Delta \lambda(\mathbf{n m})$ & Measured $\triangle \lambda(\mathbf{n m})$ \\
\hline $\mathrm{X} 310$ & 15.52 & 0.50 & 0.15 & 0.23 \\
\hline $\mathrm{X} 311$ & 26.98 & 0.86 & 0.26 & 0.1 \\
\hline $\mathrm{X} 387$ & 18.36 & 0.59 & 0.18 & 3.15 \\
\hline $\mathrm{X} 346$ & 22.59 & 0.72 & 0.22 & 0.02 \\
\hline $\mathrm{X} 367$ & 7.9 & 0.25 & 0.08 & 0.1 \\
\hline $\mathrm{X} 437$ & 4.93 & 0.16 & 0.05 & 0.08 \\
\hline
\end{tabular}

Table 3. - Comparison of calculated und measured diode peak emission wavelength shift after 2.5 billion shots.

Interestingly, there is little correlation between the calculated and measured peak wavelength shifts. For diodes with low percent degrade (X310, X367, and X437) there is a constant factor of -1.5 between the calculated and measured shifts. In contrast, the high percent degrade diodes have no apparent interdependence. This may be an indication of dissimilar diode degradation mechanisms. This behavior requires further analysis.

The diode facets were imaged using a zoom lens and beam profiler. A sample of the recorded images is shown in Figure 4. Degradation in the number of emitters was tracked over the life of the test.

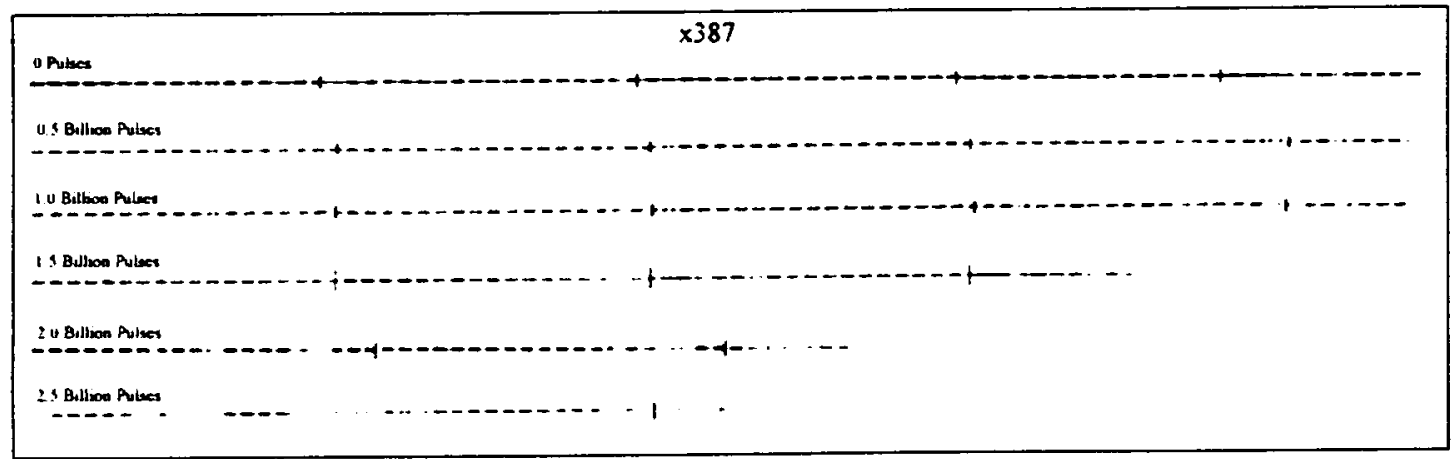

Figure 4. - Close-up images of laser diode X387 emission taken at 500 million shot intervals. A complete diode bar consists of 79 emitters. Erosion of the number of emitters is evident.

The optical power degradation per diode was compared to the decrease in number of emitters. In Figure 5 , the power per diode is divided by the number of active emitters and plotted as a function of number of shots. The ratios were normalized to the initial value. If the diode power degradation was exclusively due to a decrease in the number of active emitters, the traces would stay constant at unity. Values less than one correspond to decreased optical loading per emitter. If the power per emitter decreases as well as the number of emitters, the traces would all slope below unity. Values greater than one correspond to increased optical loading. An extreme example is diode X387. In this case, the percentage of failed emitters is substantially greater than the power degradation. It is proposed that for these failed emitters, the impedance increases, forcing more current through the active emitters. $\mathrm{X} 387$ is also the only laser diode tested to show events with stepped increase in optical power. (See Figure 1.) After the diode's power increases, the degradation rate increases. This supports the theory that more current is flowing through the active emitters. This increase in the current elevates the temperature and therefore the emission wavelength. This is clearly shown for diode $\mathrm{X} 387$ in Figure 3. 


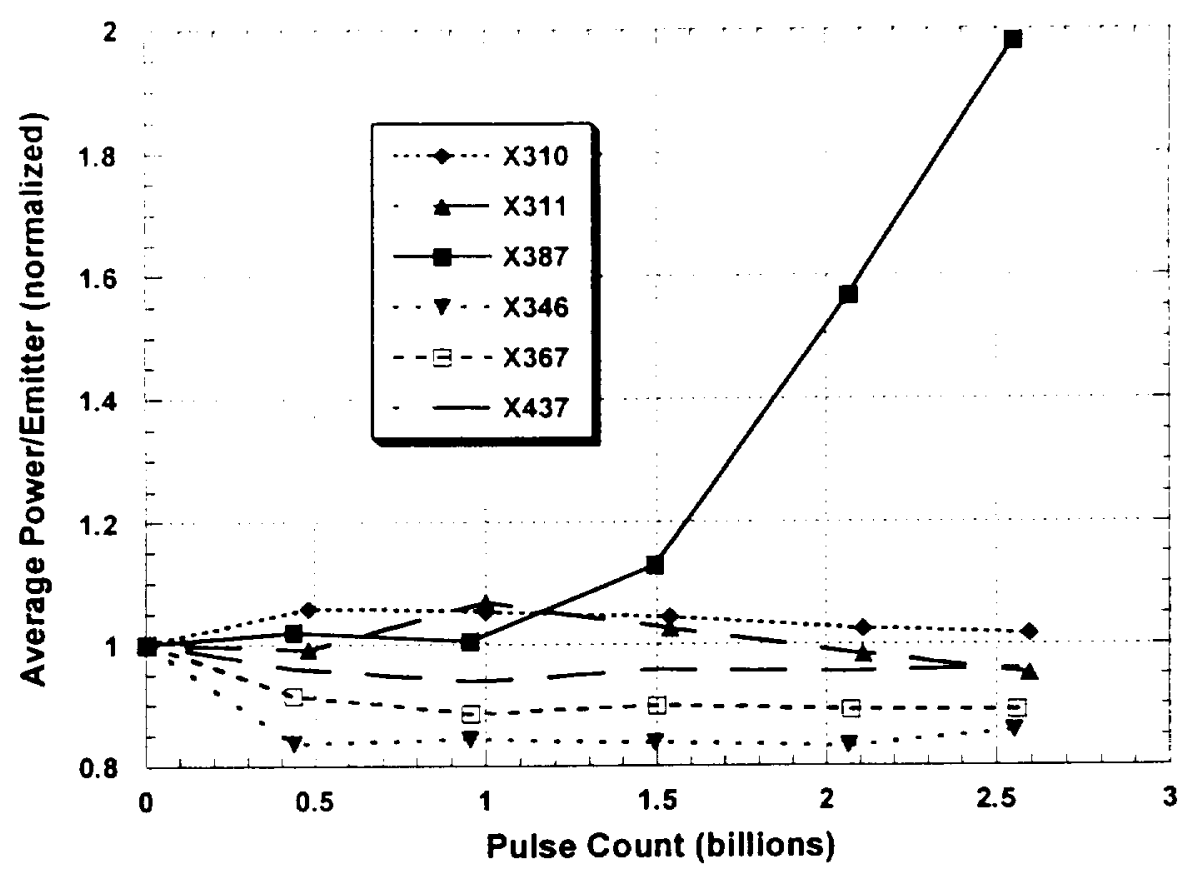

Figure 5. - Average power per emitter of SDL 3255 laser diode bars.

\section{CONCLUSIONS}

The multi-billion shot performance of QCW laser diode bars has been recorded. De-rating the optical power has been shown to improve long duration performance. Comparing diodes with a $10^{\circ} \mathrm{C}$ difference in operational temperature revealed no significant change in performance. Further investigation of degradation mechanisms is required to explain the inconsistent wavelength shifts and emitter power loading.

\section{REFERENCES}

1. R. S. Afzal, A. W. Yu and W. A. Mamakos, "The GLAS Laser Transmitter Breadboard," OSA Trends in Optics and Photonics on Advanced Solid State Lasers, C. R. Pollock and W. R. Bosenberg, eds. (Optical Society of America, Washington DC, (10), 102 (1997).

2. J. L. Dallas, R. S. Afzal, and M. A. Stephen, "Demonstration and characterization of a multi-billion shot, 2.5-mJ, 4 ns Q-switched Nd:YAG laser," App. Opt., Vol. 35, No. 9, 1427-1429 (1996).

3. M. A. Stephen, J. L. Dallas, R. S. Afzal, "Multi-billion shot high-fluence exposure of $\mathrm{Cr}^{4+}: \mathrm{YAG}$ passive Q-switch," Laser-induced Damage in Optical Materials: 1997, G. J. Exarhos, A. H. Guenther. M. R. Kozlowski, K. L. Lewis. and M. J. Soileau, eds. (1997).

4. M. Krainak, R. Afzal, M. Stephen. G. Browder, J. Haden, N. Carlson, "Performance Tests of QuasiCW Diode Pump Arrays Conducted or Sponsored by NASA Goddard Space Flight Center, " 1997 Digest of the LEOS Summer Topical Meetings: Advanced Semiconductor Lasers and Applications. 78-79, (1997). 